\title{
Synergistic Analysis of Co-combustion of Sunflower Straw and Coal Gangue
}

\author{
Guofang Yang, Xiangru Jia,* Yabin Zhao, Xinguang Huo, Changzhong Song, and Zijun \\ Zhang
}

Coal gangue and sunflower straw biomass from Xilingguole, Inner Mongolia, China and Ulanqab Tsining District, Inner Mongolia, China, respectively, were burned separately and mixed in different proportions. The synergistic effect was analyzed by comparing the actual mixed combustion curve with the theoretical mixed combustion curve. The bar chart and TR (the mean of the difference between the experimental and calculated was divided by the mean of the calculated values) value curve were used to show the synergistic effect. The results showed that the synergistic effect of coal gangue and sunflower straw was optimal when the ratio (sunflower straw:coal gangue) was 2:8.

Keywords: Biomass; Coal gangue; Synergy

Contact information: College of Energy and Power Engineering, Inner Mongolia University of Technology, Hohhot 010051, China; *Corresponding author; jxr0818@163.com

\section{INTRODUCTION}

Energy greatly influences a country's development and progress. Global primary energy consumption grew by an average of $2.2 \%$ in 2017, and China's energy consumption rose by $3.1 \%$ (NBS 2018a). For the 17th year in a row, China was the world's largest energy producer (NBS 2018a). Every year, China consumes more resources than it produces. As economic development and scientific and technological progress accelerate the pace of life, the disparity between resource consumption and production continues to grow. For China and the rest of the world, a solution to this disparity is urgently needed (NBS 2018b).

Sung et al. (2016) found that the co-combustion of biomass and bituminous coal has a synergistic effect. The thermochemical properties of coal gangue, soybean straw, sawdust, and mixtures prepared with different proportions were determined by thermogravimetric analysis. Zhou et al. (2017) found that the ignition performance and thermal reactivity of coal gangue could be improved by adding biomass. The co-pyrolysis of corncob and coal gangue in a fiber tube resistance furnace was carried out by Liu (2017). The ratios of coal gangue to corncob were $20 \%$ and $40 \%$, the temperature was over $200{ }^{\circ} \mathrm{C}$, and the co-pyrolysis of corncob and coal gangue had a certain synergistic effect. There is yet to be sufficient research on the synergistic effect of biomass and coal gangue combustion. In this paper, the co-combustion of biomass and coal gangue in different proportions was studied. The coal gangue from Xilinguole, Inner Mongolia, China and sunflower straw in Jining, Inner Mongolia, China were studied.

Although the mixing of biomass and coal gangue is a physical mixing process, the mixed combustion characteristics of biomass and coal gangue are not a simple superposition of the two combustion characteristics. Due to the different compositions 
and properties of biomass and coal gangue, there can be mutual promotion or inhibition in the process of co-firing. Therefore, to provide a strong theoretical basis for practical application in the future, it is necessary to study the interaction between biomass and coal gangue. Synergetics is the brainchild of German physicist Hermann Haken (Haken 1989). He proposed it in the 1970s as a discipline to study the laws of coordination between subsystems within a system. The theory can be summarized in three aspects (Wang et al. 2017; Pan 2018; Zhao 2018), which include synergy, the principle of servo, and the selforganization principle.

\section{EXPERIMENTAL}

\section{Preparation and Basic Characteristics of Experimental Samples}

The coal gangue came from Xilingol coal field, Inner Mongolia, China and the sunflower straw came from Ulanqab Tsining District farmland, Inner Mongolia, China. After the preliminary post-drying (First, it was put into the room for natural drying for 24 $\mathrm{h}$, and then it was put into a drying oven at $80{ }^{\circ} \mathrm{C}$ for $2 \mathrm{~h}$. The dried samples were taken out and put into a grinding mill for grinding. Finally, the test samples were taken out by method of coning and quartering.) and grinding treatment of the above experimental materials, in accordance with ASTM D197-87 (2012), post-drying at $120{ }^{\circ} \mathrm{C}$ for $12 \mathrm{~h}$, the size of sieving particles was 120 mesh.

The sunflower straw was added to lignite at weight ratio of $20 \%, 30 \%, 40 \%, 50 \%$, $60 \%, 70 \%$, and $80 \%$. The blends were mixed a total amount of $10 \mathrm{~g}$ in all proportions to ensure the uniformity. The proximate analysis, i.e. moisture (Mad), ash (Aad), volatile matter ( Vad), and fixed carbon (FCad), and the elemental analysis of materials was used to calculate the calorific value (Qb.ad) and combustion products of materials. Generally, the five elements $\mathrm{C}, \mathrm{H}, \mathrm{O}, \mathrm{N}$, and $\mathrm{S}$ are mainly analyzed in this type of assay. The proximate analysis and elemental analysis of the materials are shown in Table 1.

Table 1. Proximate Analysis Value and Element Analysis Values of Test Samples (Mass Fraction)

\begin{tabular}{|c|c|c|c|c|c|c|c|c|c|c|}
\hline \multicolumn{4}{|c|}{ Proximate Analysis } & \multicolumn{6}{c|}{ Element Analysis } \\
\hline $\begin{array}{c}\text { Sample } \\
\text { Description }\end{array}$ & $\begin{array}{c}M_{\mathrm{ad}} \\
(\%)\end{array}$ & $\begin{array}{c}A_{\mathrm{ad}} \\
(\%)\end{array}$ & $\begin{array}{c}V_{\mathrm{ad}} \\
(\%)\end{array}$ & $\begin{array}{c}F C_{\mathrm{ad}} \\
(\%)\end{array}$ & $\begin{array}{c}Q_{\mathrm{b} \cdot \mathrm{ad}}(\mathrm{kJ} \\
\left.\cdot \mathrm{kg}^{-1}\right)\end{array}$ & $\begin{array}{c}C_{\mathrm{ad}} \\
(\%)\end{array}$ & $\begin{array}{c}H_{\mathrm{ad}} \\
(\%)\end{array}$ & $\begin{array}{c}O_{\mathrm{ad}} \\
(\%)\end{array}$ & $\begin{array}{c}N_{\mathrm{ad}} \\
(\%)\end{array}$ & $\begin{array}{c}S_{\mathrm{ad}} \\
(\%)\end{array}$ \\
\hline $\begin{array}{c}\text { Coal } \\
\text { gangue }\end{array}$ & $\begin{array}{c}1.5 \\
6\end{array}$ & 69.04 & 17.07 & 12.33 & 8986 & 24.84 & 1.37 & 1.69 & 0.41 & 1.09 \\
\hline $\begin{array}{c}\text { Sunflower } \\
\text { straw }\end{array}$ & $\begin{array}{c}1.9 \\
3\end{array}$ & 8.54 & 71.69 & 17.84 & 15757 & 44.23 & 5.64 & 38.30 & 1.17 & 0.19 \\
\hline
\end{tabular}




\section{Experimental Setup and Method}

The combustion experiment was carried out via a Setaram Setsys Evo thermal analyzer (France Setaram Instrument Company, Caluire-et-Cuire, France). At the beginning of the test, the thermal analyzer was preheated for $20 \mathrm{~min}$. At the same time, Ar was used as the protecting gas and $\mathrm{N}_{2}$ was used as carrier gas $\left(\mathrm{O}_{2}\right.$ was injected during combustion). The gas flow rate was $30 \mathrm{~mL} / \mathrm{min}$. The samples, which weighed about 10 $\mathrm{mg}$, were put it into $\mathrm{Al}_{2} \mathrm{O}_{3}$ crucibles, and the furnace was heated from $40{ }^{\circ} \mathrm{C}$ to $1000{ }^{\circ} \mathrm{C}$ at a heating rate of $30{ }^{\circ} \mathrm{C} / \mathrm{min}$, and the cooling water was opened to start the test. All the tests were carried out at least twice to ensure the repeatability.

\section{SYNERGY ANALYSIS}

According to the synergy method, three methods were used to compare and analyze the combustion synergy:

(1) The theoretical values were compared with the experimental values to study the synergistic effect. TG/DTG analysis provides precise real-time information of mass variation versus time or temperature from a view of macroscopic scale, which is a common method for investigations on thermal behaviors and properties. If the theoretical calculation curves did not coincide with the experimental curves completely, then it would indicate a synergistic effect. The algorithm was as follows, Eq. 1,

$$
T G_{\text {The }}=x_{b} \xi \varpi_{b}+x_{g} \xi \varpi_{g}
$$

where $T G_{T h e}$ are the calculated data according to the "rule of mixtures" calculation, $\varpi_{\mathrm{b}}$ is a separate biomass combustion of weight loss rate value, $\varpi_{\mathrm{g}}$ is the experimental value of weight loss rate of coal gangue burning alone, $x_{\mathrm{b}}$ is the proportion of biomass in mixed samples, and $x_{\mathrm{g}}$ is the proportion of coal gangue in mixed solid samples,

$$
D T G_{T h e}=x_{b} \xi_{b}+x_{g} \xi_{a}
$$

where $D T G_{T h e}$ are the calculated data according to the "rule of mixtures" calculation, $\xi_{\mathrm{b}}$ is the experimental value of weight loss rate of biomass burning alone, $\xi_{\mathrm{g}}$ is the experimental value of weight loss rate of coal gangue burning alone $x_{\mathrm{b}}$ is the proportion of biomass in mixed samples, and $x_{\mathrm{g}}$ is the proportion of coal gangue in mixed solid samples.

(2) The following formula (Eq. 3) was used to process the data and draw a histogram to compare and analyze the effect of synergy. Equation 3 is as follows:

$$
\left|\frac{T G_{\mathrm{Ex}}-T G_{\mathrm{The}}}{T G_{\mathrm{The}}}\right| \times 100 \%
$$

(3) An impact index, TR, was introduced to describe the degree of interaction between each stage. The mean of the difference between the experimental and calculated values was divided by the mean of the calculated values (recorded as TR) to analyze the effects of the combustion process. The formula for TR was as follows (Eq. 4) (Liang 2017),

$$
T R=\left[\sum_{i=1}^{n}\left(\xi_{\exp }^{i}-\xi_{\text {cal }}^{i}\right)\right] / n \xi_{\text {cal }}^{\text {mean }}
$$


where $\xi_{\exp }^{i}$ is the experimental value of point $\mathrm{I}, \xi_{\mathrm{cal}}^{i}$ is the calculated value of point I, and $\xi_{\text {cal }}$ is the average of calculated values. When TR $>0$, the reaction is benefited. When $\operatorname{Tr}<0$, the reaction is inhibited.

\section{Synergistic Analysis Results}

As displayed in Table 1, the carbon content of sunflower straw was higher than that of coal gangue, which meant that it needed more time to complete the pyrolysis process. The $\mathrm{H} / \mathrm{C}$ atomic ratio of sunflower straw was 2.31 times that of coal gangue. It is known that high $\mathrm{H}$ content can produce more $\mathrm{H}$ free radicals during pyrolysis process, which helps to improve the quality of liquid and gaseous fuels (Li et al. 2015). Therefore, more $\mathrm{H}$ free radicals could be expected to be generated when blending sunflower straw in coal gangue, leading a promoting synergistic effect. Moreover, the sunflower straw had high volatile matter content $(71.7 \%)$, which suggests high reactivity and volatility. This favored an increase in oil yield (Grioui et al. 2019). Therefore, the co-combustion process makes fuller use of the advantages of each fuel and to make up for their shortcomings.

The experimental curves and theoretical curves (the curves calculated according to the "rule of mixtures") of the TG and DTG of sunflower straw and coal gangue mixed combustion in different proportions are shown in Fig. 1. The experimental and theoretical curves did not completely coincide, and most of the theoretical curves were above the actual curves. The results showed that sunflower straw had a synergistic effect when it was mixed with coal gangue in different proportions.

Comparison of the TG experimental curve with the theoretical curve found that the weight loss rate in the actual mixed combustion process was greater than the theoretical mixed combustion. Comparison of the DTG experimental curve with the theoretical curve showed that the actual weight loss of the DTG curve was lower than the theoretical weight loss in the devolatilization and combustion stages of fixed carbon. This was because the synergy between the two phases was not shown in the magnitude of the weight loss, but in whether the combustion reaction was more complete.

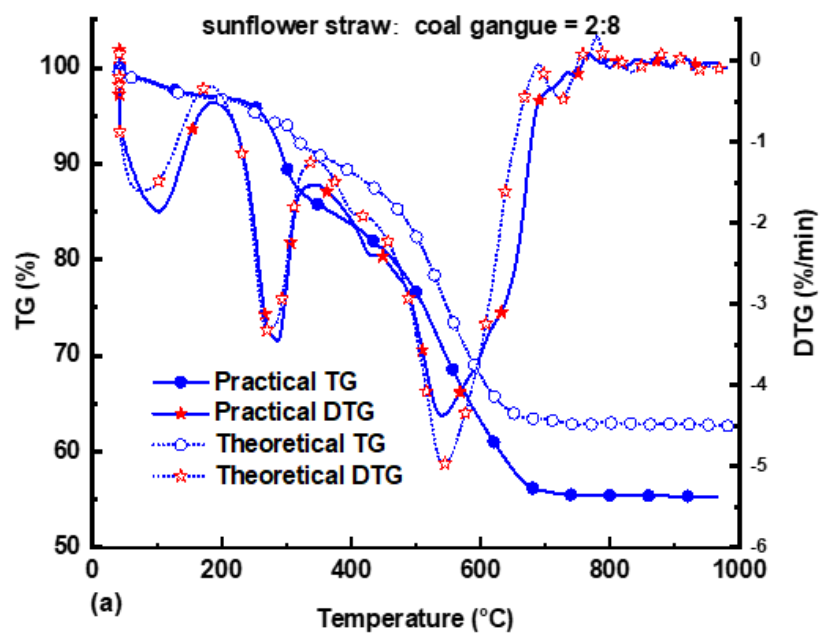

Yang et al. (2020). "Synergism of co-combustion," BioResources 15(4), 7770-7779. 

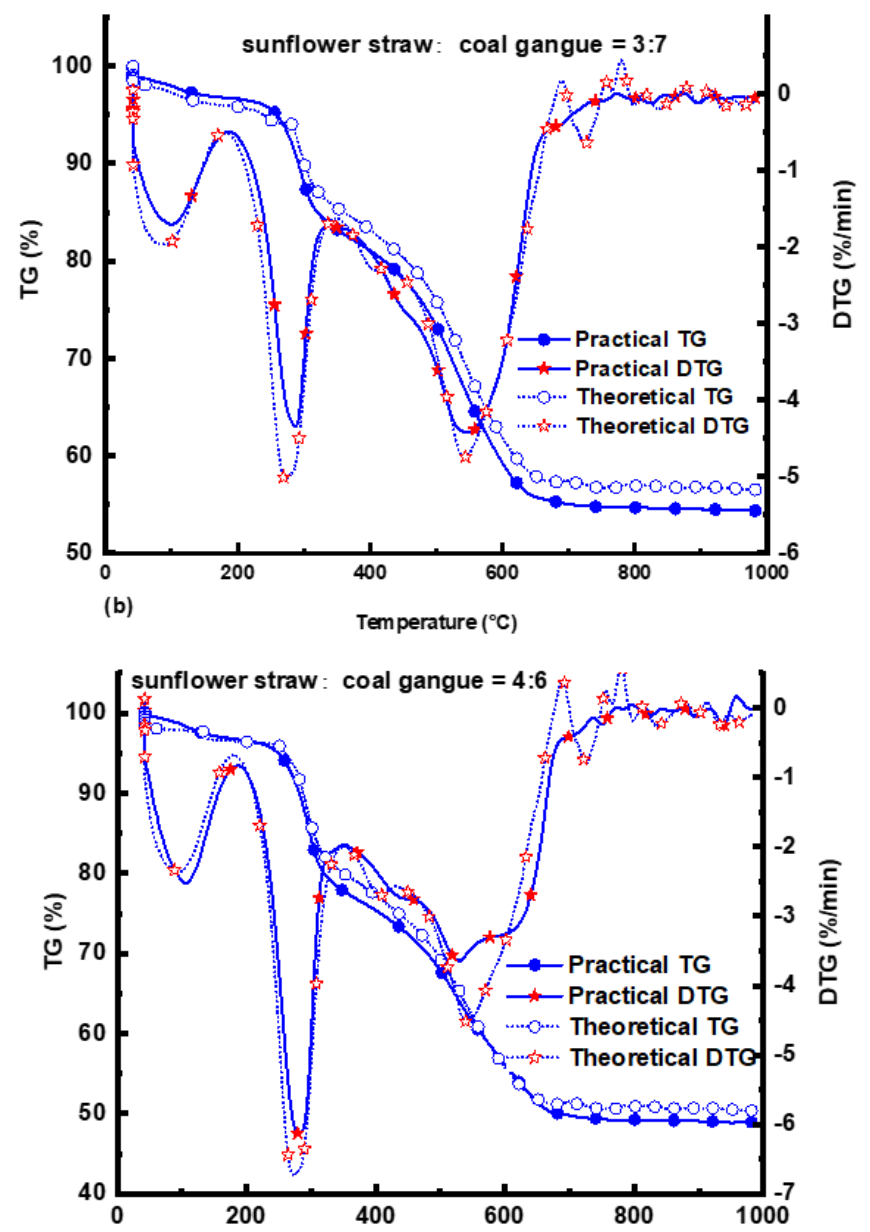

(c)

Temperature $\left({ }^{\circ} \mathrm{C}\right)$

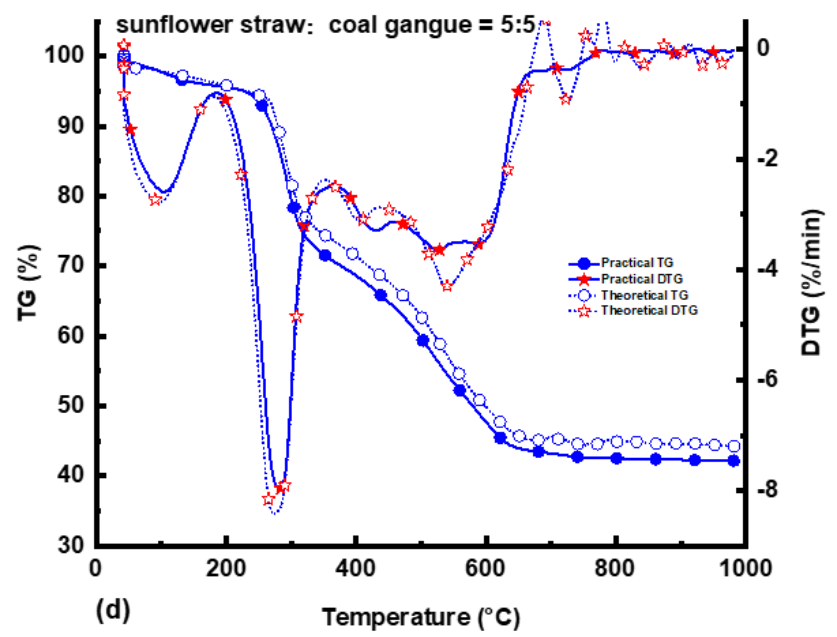




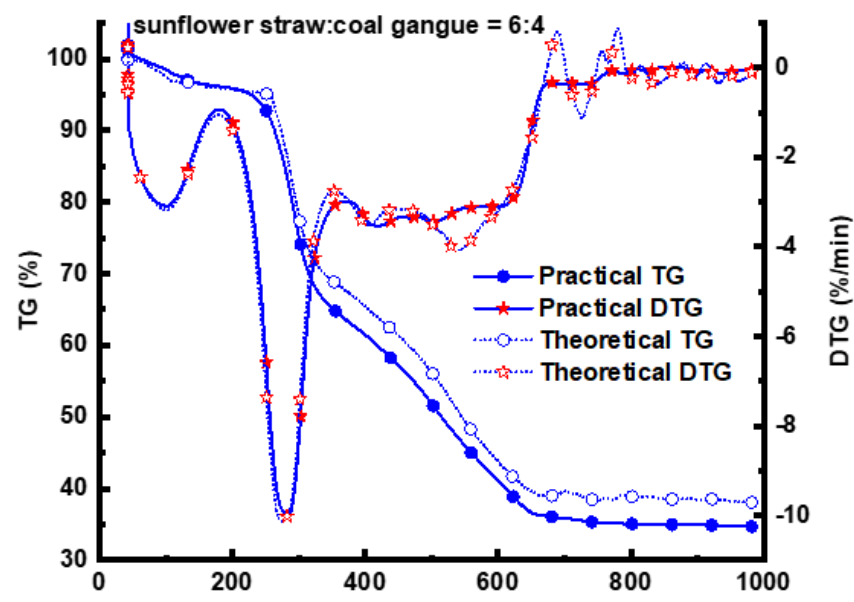

(e) Temperature $\left({ }^{\circ} \mathrm{C}\right)$
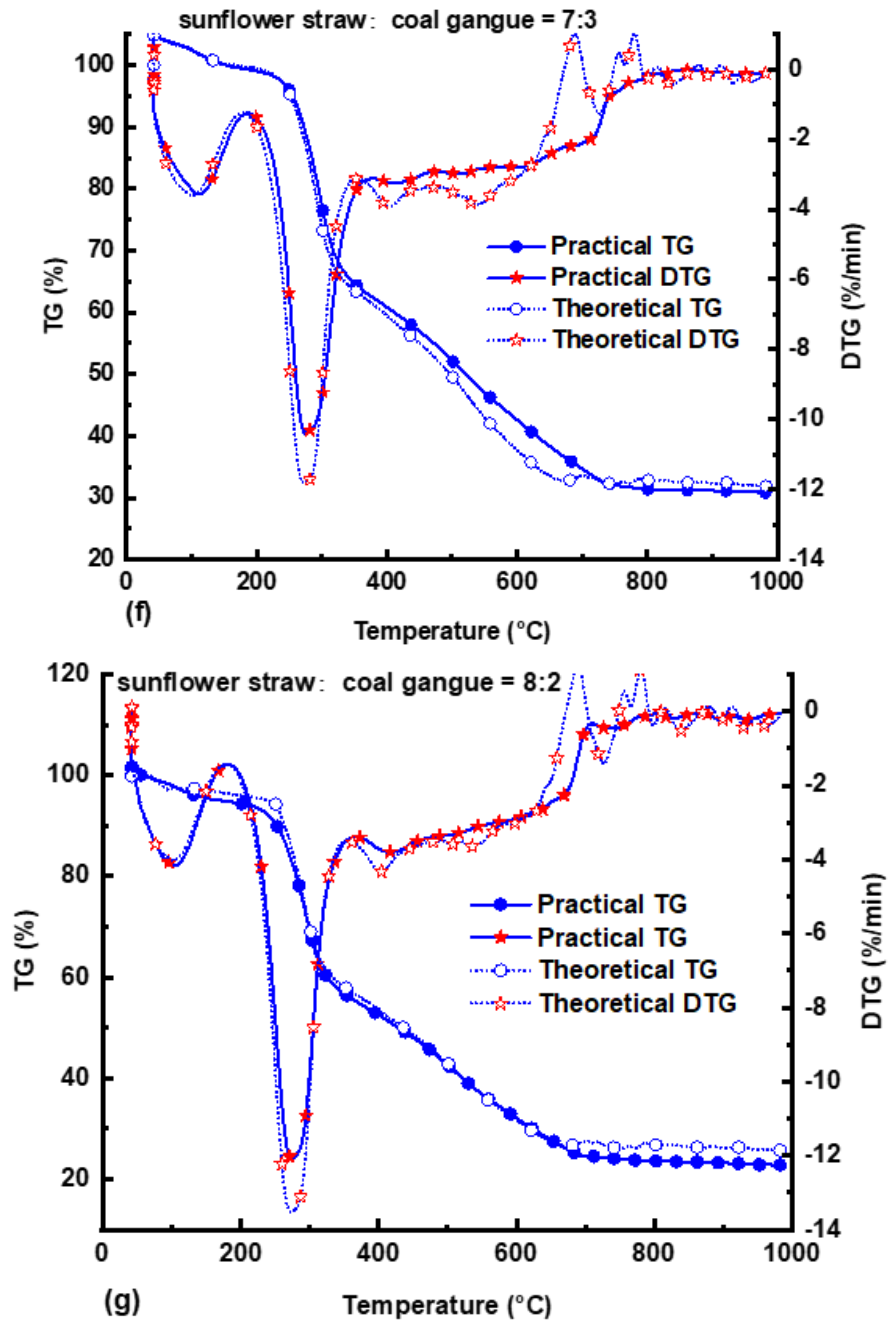

Fig. 1. The TG and DTG curves of the theoretical and experimental values of sunflower straw and coal gangue mixed combustion in different ratios: (a) 2:8; (b) 3:7; (c) 4:6; (d) 5:5; (e) 6:4; (f) 7:3; (g) $8: 2$ 
The theoretical and experimental values of the mixed combustion of sunflower straw and coal gangue were calculated to obtain the data shown in Table 2 and the column graph shown in Fig. 2. The results showed that sunflower straw and coal gangue ratios of $2: 8$ and 8:2 were more suitable than the other ratios.

The TR value curve of the mixed combustion of sunflower straw and coal gangue is shown in Fig. 3. Figure 3 shows that the TR value of the mixed combustion of sunflower straw and coal gangue was mostly greater than 0 , which indicated that the whole process benefited combustion. The TR value curve of sunflower straw and coal gangue at a ratio of 2:8 was better than other ratios. In other words, there was a maximum in synergy when the ratio of sunflower straw to coal gangue ratio was $2: 8$. The reason for this phenomenon was that pyrolysis of sunflower straw's cellulose produces a large number of hydrogen radical fragments, which promoted the cracking of coal gangue (Wu et al. 2018; 2019a,b,c).

The TR value of the mixed combustion of two kinds of biomass and coal gangue was less than zero at the initial stage of combustion, which was unfavorable for the reaction. Because the initial combustion is mainly water evaporation, as a part of the mixed sample, biomass is weaker than coal gangue in water evaporation capacity because the water content of both biomass is larger than that of coal gangue. Meng et al. (2016) reported that synergetic effect from co-combustion could be attributed to the formation of $\mathrm{OH}$ and $\mathrm{H}$ radicals from the combustion process of biomass. Thus, the radicals transferred from biomass to the coal gangue structure, leading to the improvement in the decomposition of coal gangue.

In general, the synergistic effects of coal gangue and sunflower straw is mainly derived from three aspects: (1) the effects of different components, including volatile matter, fixed carbon and ash composition; (2) secondary reaction between pyrolysis products, including free radical reaction and gasification reaction (Li et al, 2015); and (3) the different thermal conductivity between fuels (Li et al. 2015).

Table 2. Data Processing Table

\begin{tabular}{|c|c|}
\hline Ratio of Sunflower Straw:Coal Gangue & $\left|\frac{T G_{\text {Test }}-T G_{\text {Theoretical }}}{T G_{\text {Theoretical }}}\right| \times 100 \%$ \\
\hline $2: 8$ & $12.8 \%$ \\
\hline $3: 7$ & $4.6 \%$ \\
\hline $4: 6$ & $3.3 \%$ \\
\hline $5: 5$ & $6.7 \%$ \\
\hline $6: 4$ & $8.3 \%$ \\
\hline $8: 3$ & $5.0 \%$ \\
\hline $8: 2$ & $12.5 \%$ \\
\hline
\end{tabular}




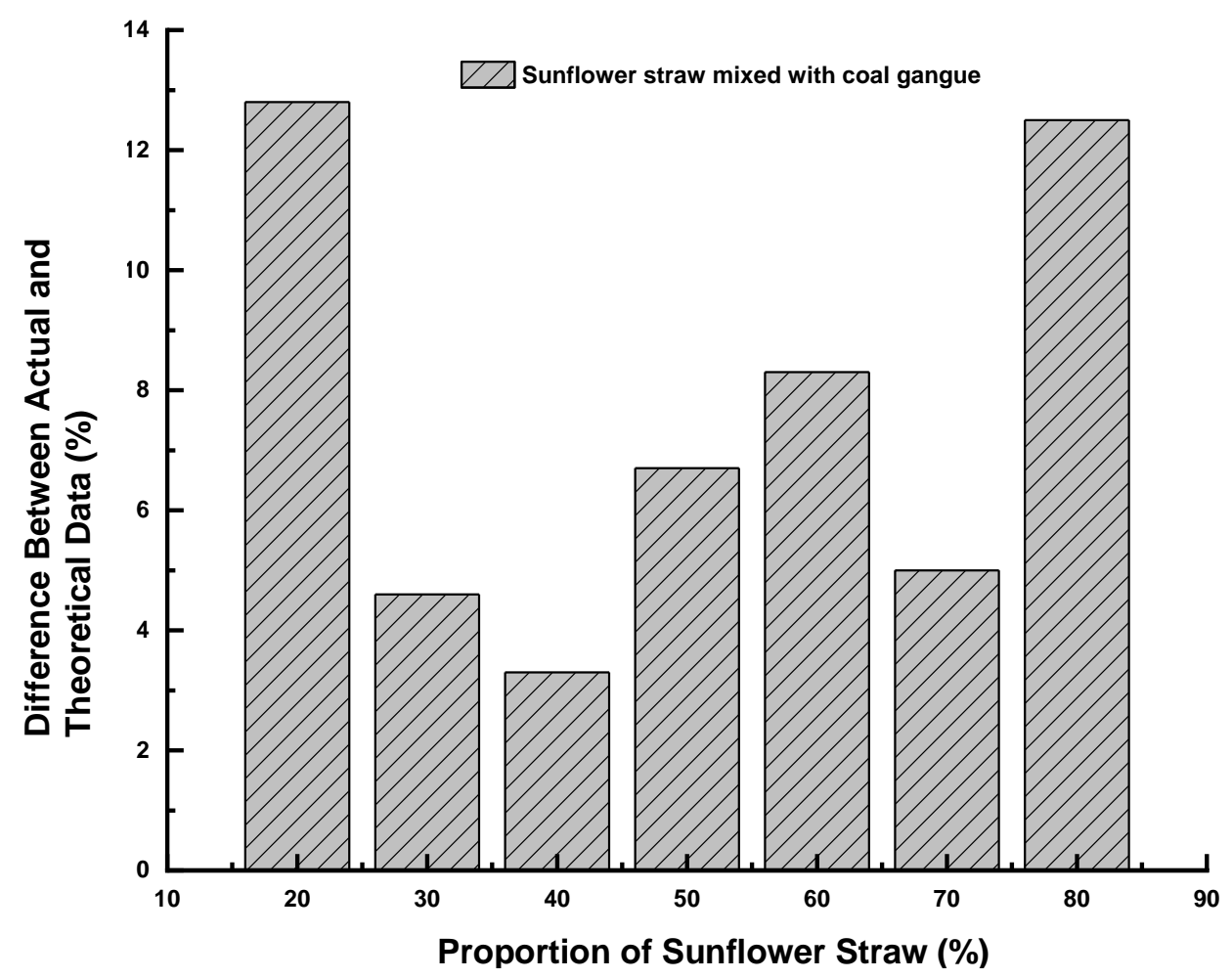

Fig. 2. Collaborative column analysis diagram

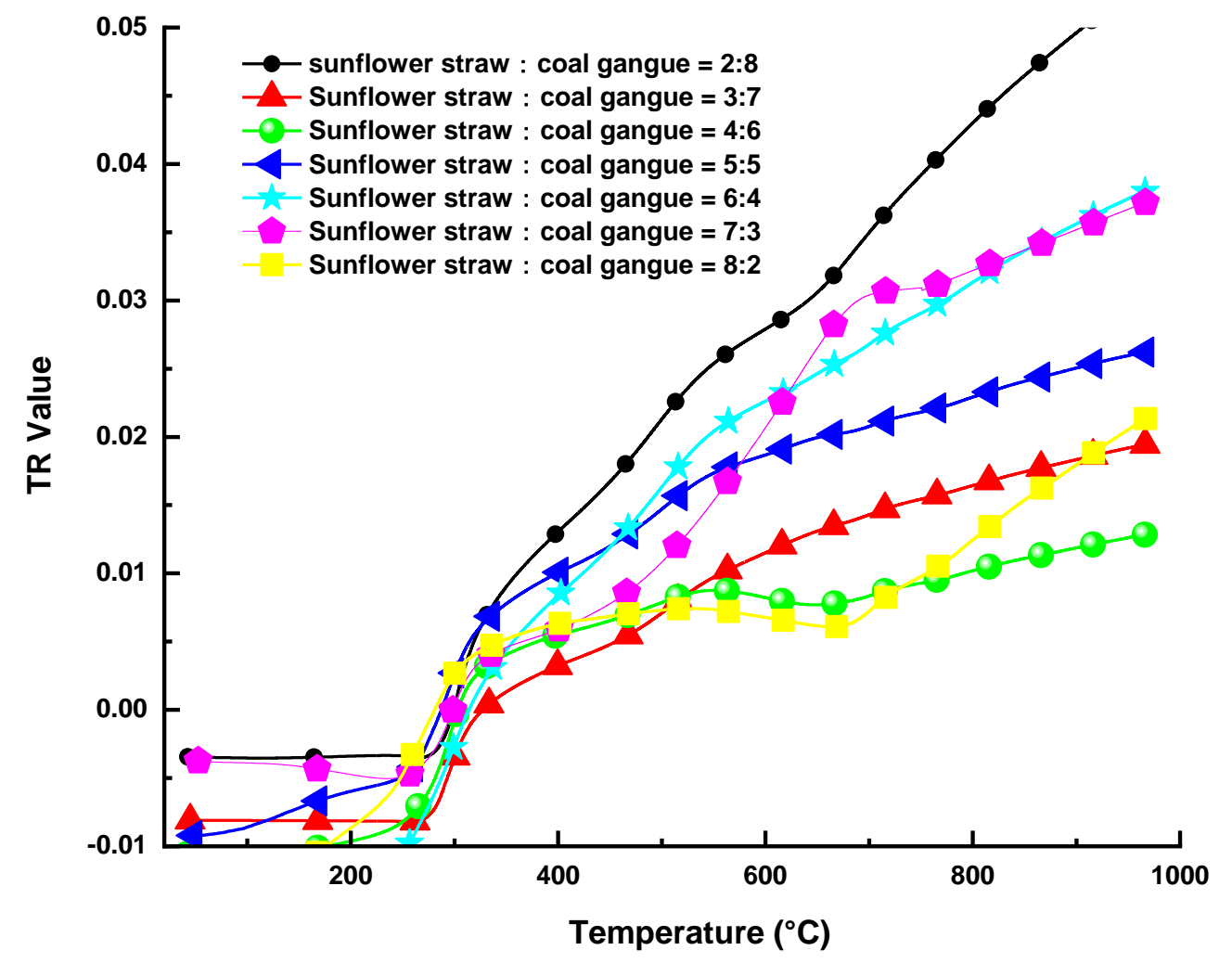

Fig. 3. The TR value curve 


\section{CONCLUSIONS}

1. The theoretical TG curve of mixed combustion, based on a linear rule of mixtures calculation, did not completely coincide with the actual TG curve of the same mixing ratio, and the theoretical DTG curve of mixed combustion did not completely coincide with the actual DTG curve of the same mixing ratio. These findings showed that there was a synergistic effect between biomass and coal gangue beyond the simple superimposition of biomass and coal gangue combustion alone.

2. Comparison of the column charts revealed that the biomass and coal gangue ratios of 2:8 and 8:2 were better than the other ratios. In addition, the synergistic effect of mixed combustion of sunflower straw and coal gangue was better than that of corn straw and coal gangue.

3. The TR curve showed that the best synergistic effect was obtained when the ratio of biomass to coal gangue was 2:8 in the mixed combustion test.

\section{ACKNOWLEDGEMENTS}

This work was supported by the Research Program of Science and Technology at Universities of Inner Mongolia Autonomous Region (No. NJZY18082).

\section{REFERENCES CITED}

ASTM D197-87 (2012). "Standard test method for sampling and fineness test of pulverized coal," ASTM International, West Conshohocken, PA, USA.

Grioui, N., Halouani, K., and Agblevor, F. A. (2019). "Assessment of upgrading ability and limitations of slow co-pyrolysis: Case of olive mill wastewater sludge/waste tires slow co-pyrolysis," Waste Manage 92, 75-88. DOI: 10.1016/j.wasman.2019.05.016

Haken, H. (1989). Higher Synergetics, Science Press, Beijing, China.

Li, S., Chen, X., Liu, A., Wang, L., and Yu, G. (2015). "Co-pyrolysis characteristic of biomass and bituminous coal," Bioresource Technology 179, 414-420.

DOI: 10.1016/j.biortech.2014.12.025

Liang, X. (2017). Study on the Synergy Between Semi-coke and Dry Corn Straw in Oil Shale, Tohoku Electric Power University, Jilin, China.

Liu, X. (2017). Study on the Co-pyrolysis Behavior of Corncob, Coal Gangue and Plastic with Various Additives, Shanxi Normal University, Shanxi, China.

Meng, H., Wang, S., Chen, L., Wu, Z., and Zhao, J. (2016). "Study on product distributions and char morphology during rapid co-pyrolysis of Platanus wood and lignite in a drop tube fixed-bed reactor," Bioresource Technology 209, 273-281.

DOI: $10.1016 /$ j.biortech.2016.03.024

National Bureau of Statistics (NBS) (2018a). BP World Energy Statistics Yearbook, National Bureau of Statistics, Beijing, China.

National Bureau of Statistics (NBS) (2018b). China Statistical Yearbook, National Bureau of Statistics, Beijing, China. 
Pan, L. (2018). "Transformer fault diagnosis based on synergetic theory," Guangxi Electric Power 41(4), 8-13. DOI: 10.16427/j.cnki.issn1671-8380.2018.04.002

Sung, Y., Lee, S., Kim, C., Jun, D., Moon, C., Choi, G., and Kim, D. (2016). "Synergistic effect of co-firing woody biomass with coal on $\mathrm{NO}_{\mathrm{x}}$ reduction and burnout during airstaged combustion," Experimental Thermal and Fluid Science 71(1), 114-125. DOI: 10.1016/j.expthermflusci.2015.10.018

Wang, X., Rui, Z., Zeng, Y., Ji, H., Du, Z., and Rao, Q. (2017). "Synergetic effect of oxygen vacancy and $\mathrm{Pd}$ site on the interaction between $\mathrm{Pd} /$ Anatase $\mathrm{TiO}_{2}(101)$ and formaldehyde: A density functional theory study," Catalysis Today 297(5), 151-158. DOI: 10.1016/j.cattod.2017.06.037

Wu, H., Zheng, J., and Wang, G. (2019a). "Catalytic liquefaction of switchgrass in isobutanol/ water system for bio-oil development over bifunctional NiHPMo/Fe $\mathrm{O}_{4} @ \mathrm{Al}-\mathrm{MCM} 41$ catalysts," Renewable Energy 141, 96-106. DOI: 10.1016 / j.renene.2019.03.135

Wu, Z., Li, Y., Xu, D., and Meng, H. (2019b). "Co-pyrolysis of lignocellulosic biomass with lowquality coal: Optimal design and synergistic effect from gaseous products distribution," Fuel 236, 43-54. DOI: 10.1016/j.fuel.2018.08.116

Wu, Z., Li, Y., Zhang, B., Yang, W., and Yang, B., (2019c). "Co-pyrolysis behavior of microalgae biomass and low-rank coal: kinetic analysis of the main volatile products," Bioresource Technology 271, 202-209. DOI: 10.1016/j.biortech.2018.09.076

Wu, Z., Yang, W., Li, Y., and Yang, B. (2018). “Co-pyrolysis behavior of microalgae biomass and low-quality coal: products distributions, char-surface morphology, and synergistic effects," Bioresource Technology 255, 238-245. DOI:10.1016/j.biortech.2018.01.141

Zhao, M. (2018). Research on Control Strategy of Permanent Magnet Synchronous Motor Based on Synergetic Theory, Southwest Jiaotong University, Xian, China.

Zhou, C., Liu, G., Xu, Z., Sun, H., and Lam, P. K. (2017). "The retention mechanism, transformation behavior and environmental implication of trace element during cocombustion coal gangue with soybean stalk," Fuel 189(1), 32-38. DOI: 10.1016/j.fuel.2016.10.093

Article submitted: May 11, 2020; Peer review completed: July 3, 2020; Revised version received and accepted: July 15, 2020; Published: August 27, 2020.

DOI: $10.15376 /$ biores. 15.4.7770-7779 